\title{
Programa Selo Município Verde e a efetividade dos Objetivos do Desenvolvimento Sustentável
}

\section{Green Municipality Seal Program and effectiveness of Sustainable Development Goals}

\author{
Dayana Rodrigues de Oliveira1 ${ }^{\text {(D) }}$ https://orcid.org/0000-0003-0089-6313 \\ Ana Karolina Silva de Lima² (i) https://orcid.org/0000-0003-1536-5195 \\ Nájila Rejanne Alencar Julião Cabral ${ }^{1}$ (i) https://orcid.org/0000-0003-0960-9587 \\ Patrícia Verônica Pinheiro Sales Lima ${ }^{3}$ (D) https://orcid.org/0000-0002-6622-3640
}

\section{Resumo}

A dificuldade na internalização de políticas públicas no território nacional demonstra que é imprescindível a atuação da gestão local ambientalmente adequada para alcançar o cumprimento das metas dos Objetivos do Desenvolvimento Sustentável. O Programa Selo Município Verde é uma certificação ambiental cearense, iniciada em 2003, com o propósito de fortalecer a agenda ambiental municipal. Este trabalho teve como objetivo analisar as relações entre os indicadores ambientais do Programa com as metas dos Objetivos do Desenvolvimento Sustentável. A presente pesquisa documental, de abordagem qualitativa, teve por método a análise de conteúdo de Bardin, com coleta de dados de base secundária, analisando-se os 5 eixos do Programa quanto à Política Municipal de Meio Ambiente; Saneamento Ambiental e Saúde Pública; Recursos Hídricos; Agricultura Sustentável; Biodiversidade e Mudanças Climáticas. Os resultados indicam que o Programa possui aderência aos Objetivos 1, 2, 3, 4, 6, 8, 9, 11, 12, 13, 15, 16 e 17 da Agenda 2030. Concluise que os eixos analisados do Programa Selo Município Verde demonstram ter relação com as diferentes metas dos Objetivos do Desenvolvimento Sustentável na consecução da Agenda 2030, o que pode significar que a certificação ambiental cearense é uma ferramenta adequada e catalisadora na gestão local para atingir o Desenvolvimento Sustentável.

Palavras-chave: Objetivos de Desenvolvimento Sustentável; Programa Selo Município Verde; certificação ambiental.

\begin{abstract}
The difficulty in internalizing public policies in the national territory demonstrates that it is essential to have an environmentally adequate local management performance in order to achieve Sustainable Development Goals. The Green Municipality Seal Program is an environmental certification from Ceará, started in 2003, with the purpose of strengthening municipal environmental agenda. This work aimed to analyze the relationship between the Program environmental indicators and Sustainable Development Goals. This documental research, with a qualitative approach, used content analysis method by Bardin, with secondary data collection, analyzing five axes of the Program regarding the Municipal Environmental Policy; Environmental Sanitation and Public Health; Water resources; Sustainable Agriculture; Biodiversity and Climate Change. The results indicate that Green Municipality Seal Program adheres to Goals 1, 2, 3, 4, 6, 8, 9, 11, 12, 13, 15, 16 and 17 of Agenda 2030. The analyzed axes of the Green Municipality Seal Program demonstrated that they are related to the different targets of the Sustainable Development Goals in achieving the 2030 Agenda, which may mean that Ceará's environmental certification is an adequate and catalyzing tool in local management to achieve Sustainable Development.
\end{abstract}

Keywords: Sustainable Development Goals; Green Municipality Seal Program; environmental certification.

\footnotetext{
1 Instituto Federal de Educação, Ciência e Tecnologia do Ceará, Departamento da Construção Civil. Av. Treze de Maio, 2081, Campus Fortaleza, 60040-531, Fortaleza, CE, Brasil. Correspondência para/Correspondence to: N. R. A. J. CABRAL.E-mail: najila@ifce.edu.br

${ }^{2}$ Consultora autônoma. Fortaleza, CE, Brasil.

3 Universidade Federal do Ceará, Centro de Ciências Agrárias, Departamento de Economia Agrícola. Fortaleza, CE, Brasil.
} 


\section{Introdução}

A preocupação com o meio ambiente é expressa como uma das mais relevantes pautas abordadas no cenário atual, a qual pode ser entendida como o resultado de décadas de debates cuja finalidade consistia na busca pelo entendimento da situação em que se encontrava o meio ambiente e seus recursos naturais, os dados gerados e as possíveis soluções para que pudessem proporcionar uma melhor qualidade ambiental e, consequentemente, qualidade de vida (Lima, 2020). Muitos desses debates aconteceram no âmbito de conferências nacionais e internacionais, como é o caso da Conferência das Nações Unidas para o Meio Ambiente Humano (CNUMAH).

Em um cenário mais atual, a Declaração do Milênio adotada pela Cúpula do Milênio das Nações Unidas reuniu 8 Objetivos de Desenvolvimento do Milênio (ODM), com metas a serem assumidas pelos Estados-membros da ONU com horizonte de tempo de 15 anos, como a redução da pobreza extrema, a disseminação de condições sanitárias adequadas e a defesa pela educação (Roma, 2019). Em âmbito federal, o Instituto de Pesquisa Econômica Aplicada (IPEA) e o Instituto Brasileiro de Geografia e Estatística (IBGE) ficaram encarregados de adequar os ODM às prioridades nacionais (Roma, 2019).

Decorrido o período de tempo dos ODM, sediou-se a Cúpula de Desenvolvimento Sustentável cujo resultado foi a adoção da Agenda 2030, um plano de ação global que contribuirá para a sustentabilidade do planeta, com 17 Objetivos de Desenvolvimento Sustentável (ODS) compostos por 169 metas, as quais dão continuidade ao trabalho iniciado pelos ODM e asseguram o compromisso de não deixar ninguém para trás (Programa das Nações Unidas para o Desenvolvimento, 2020).

No Brasil, o Instituto de Pesquisa Econômica Aplicada (IPEA) deu publicidade ao documento contendo as metas nacionais, colaborando com os compromissos firmados de alinhamento com os ODS (Instituto de Pesquisa Econômica Aplicada, 2018). Em relação à Agenda 2030, Neves (2020) afirma que esta foi criada partindo do conhecimento de que o ambiente urbano é essencial nessa trajetória, sendo assim de extrema importância uma gestão pública municipal que incorpore os ODS.

No Estado do Ceará, em 2003, foi criado o programa de certificação ambiental pública denominado Programa Selo Município Verde (PSMV), coordenado pela Secretaria de Estado do Meio Ambiente (SEMA), tem por objetivo avaliar os municípios cearenses em relação ao cumprimento de práticas sustentáveis, além de incentivar a criação e implementação destas (Secretaria do Meio Ambiente do Ceará, 2005), fortalecendo a agenda ambiental municipal. Programa de certificação e sustentabilidade

A $13^{a}$ edição do PSMV é composta por cinco eixos temáticos, sendo eles: Política Municipal de Meio Ambiente, Saneamento Ambiental e Saúde Pública, Recursos Hídricos, Agricultura sustentável e Biodiversidade e de mudanças climáticas.

Conforme Cabral, Lima e Azevedo (2019), os indicadores ambientais do PSMV estão assim distribuídos: eixo 1 - Política Municipal de Meio Ambiente, com quatro indicadores: estrutura de 
meio ambiente (I1); efetividade dos Conselhos Municipais de Defesa do Meio Ambiente (I2); implementação da Política Municipal de Meio Ambiente (I3) e implementação de tecnologias sustentáveis (14); eixo 2 - Saneamento Ambiental e Saúde Pública, com cinco indicadores: gestão integrada dos resíduos sólidos (15); disposição final de resíduos sólidos urbanos (16); inclusão social dos catadores de materiais recicláveis (17), infestação por Aedes aegypti (18) Sistema de esgotamento sanitário e sistema de abastecimento de água (19); eixo 3 - Recursos Hídricos, com um indicador Melhoria da qualidade da água (110); eixo 4 - Agricultura Sustentável, com dois indicadores: Manejo sustentável da produção agropecuária (111) e capacitação em agricultura sustentável (112); e eixo 5 - Biodiversidade com quatro indicadores: Unidades de Conservação municipais (I13); áreas verdes urbanas (I14); preservação e conservação da biodiversidade (I15) e controle de desmatamento e queimada (I16).

A participação do município é voluntária e sua inscrição é deferida mediante comprovação da existência e do funcionamento do Conselho Municipal de Defesa de Meio Ambiente (COMDEMA), sendo este o único pré-requisito exigido obrigatoriamente. Destaca-se que o resultado das avaliações do PSMV é o Índice de Sustentabilidade Ambiental (ISA), que tem potencial para guiar a redistribuição de incentivos econômicos àqueles municípios com melhor desempenho ambiental (Cabral et al., 2008).

A metodologia do PSMV permite a avaliação de 16 indicadores ambientais classificados nas dimensões de sustentabilidade ambiental, social, econômica e institucional. Cada um dos indicadores ambientais atende à estrutura de Pressão-Estado-Resposta (PER) que, segundo Cabral, Lima e Azevedo (2019) consiste em relacionar as chamadas "fontes de pressão" no meio ambiente, o estado ou situação em que se encontra o meio e as soluções e métodos utilizados como resposta à problemática. Os 16 indicadores do PSMV são subdivididos em 67 variáveis ambientais (Cabral; Lima; Azevedo, 2019).

O alcance das metas dos ODS dependerá de readequação de políticas públicas (em âmbito federal, estadual e municipal). Assim, para a governança vigente é necessário enfrentar os desafios de implementação de políticas ambientais territoriais nos municípios do Estado do Ceará, dependendo do alinhamento do arranjo institucional, com objetivo de direcionar o desenvolvimento de cidades sustentáveis, através da incorporação dos ODS na gestão pública municipal.

Desse modo, justifica-se estudar a aderência do PSMV na mobilização de esforços para implementar a Agenda 2030 para o Desenvolvimento Sustentável, visto que uma das maiores dificuldades na disseminação dos ODS está na internalização de políticas públicas voltadas a esse alcance. O propósito deste estudo foi analisar as relações entre os indicadores ambientais dos cinco eixos do PSMV com as metas dos Objetivos do Desenvolvimento Sustentável. 


\section{Materiais e Métodos}

O presente estudo documental se caracteriza como pesquisa com abordagem qualitativa e analisa dados coletados de forma secundária. O método da investigação seguiu a análise de conteúdo de Bardin (2011), com suas três etapas: fase de pré-análise, descrição analítica e interpretação referencial.

$\mathrm{Na}$ primeira fase, pré-análise, foram escolhidos os documentos a serem analisados e realizada a leitura da base de dados para a identificação da representatividade e organização do material. Os dados secundários foram extraídos do Manual Técnico Programa Selo Município Verde - 13 $3^{a}$ edição (Cabral; Lima; Azevedo, 2019) e do Documento Agenda 2030 ODS metas nacionais dos Objetivos do Desenvolvimento Sustentável: proposta de adequação Instituto de Pesquisa Econômica Aplicada, 2018).

A segunda fase consistiu na exploração do material ou descrição analítica, segundo Bardin (2011) apresentando as prováveis aplicações da análise de conteúdo como um método de categorias que permite a classificação dos componentes do significado da mensagem em espécie de gavetas. Assim, os dados foram tratados por meio de quadros temáticos relacionando-se as distintas metas dos ODS aos indicadores ambientais do PSMV, para posterior interpretação dos resultados, na fase seguinte.

A última etapa consistiu no tratamento dos resultados e sua interpretação que, de acordo com Dos Santos (2012), nesta fase o pesquisador retorna ao referencial teórico, procurando embasar as análises, dando sentido à interpretação. Dessa maneira, foi feita a interpretação dos dados que foram categorizados em quadros, buscando respaldar legalmente a análise.

\section{Resultados e Discussão}

O Eixo 1 corresponde à Política Municipal de Meio Ambiente e possui quatro indicadores ambientais: Estrutura do Meio Ambiente, Efetividade dos Conselhos Municipais de Defesa do Meio Ambiente, Implementação da Política Municipal de Educação Ambiental e Implementação de Tecnologias Sustentáveis, cujas variáveis ambientais totalizam 22. O Quadro 1 traz o resultado deste eixo, demonstrando a relação entre os indicadores e a aderência às metas dos ODS. A meta de cada ODS pode ser encontrada em IPEA (Instituto de Pesquisa Econômica Aplicada, 2018). 
Quadro 1 - Indicadores Ambientais do Eixo Temático 1: Política Municipal de Meio Ambiente e sua aderência aos ODS

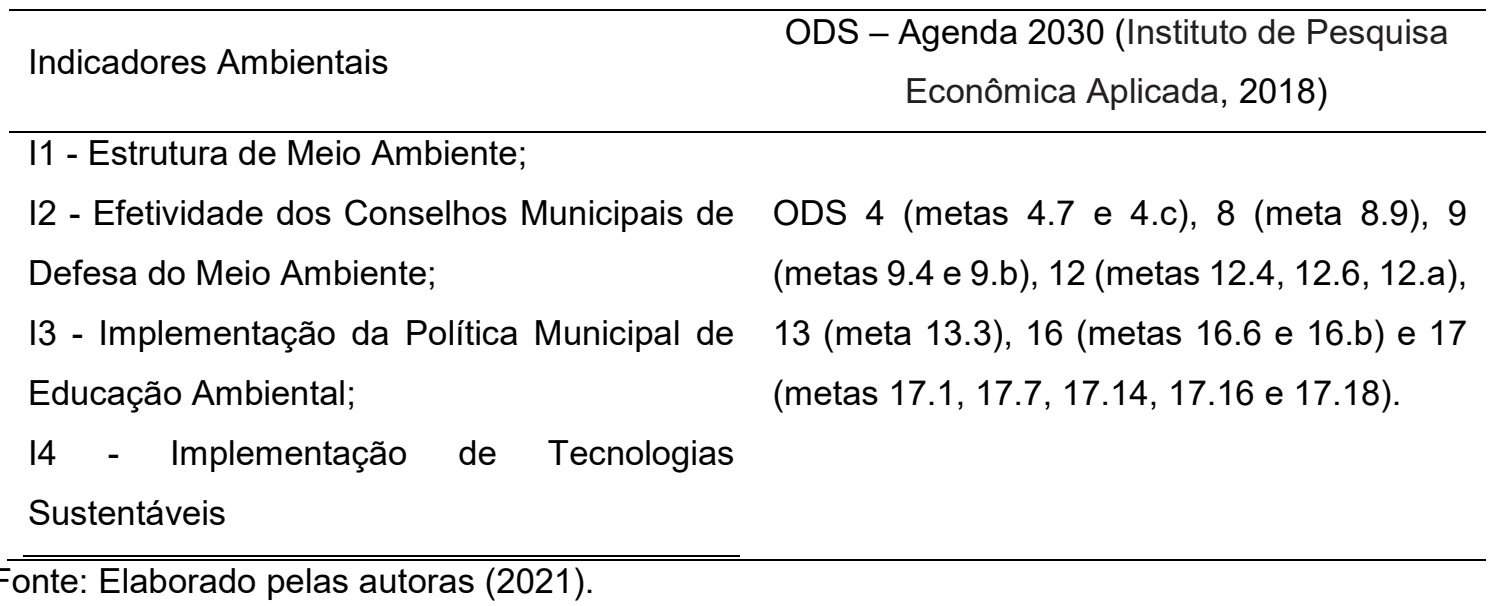

Consoante à Política Nacional de Meio Ambiente, Lei nº 6.938/1981, e à Lei Complementar n ${ }^{0}$ 140/2011, é atribuição do município a formulação e a execução da Política Municipal de Meio Ambiente, da mesma forma que compete a este ente federativo, no que couber, executar o exercício das políticas de meio ambiente em âmbito federal e estadual. Dessa maneira, respalda-se a relação do indicador I1 - Estrutura de Meio Ambiente com os ODS 16 (metas 16.6 e 16.b) e 17 (metas 17.1 e 17.14).

A coerência das políticas públicas é essencial para alcançar o desenvolvimento sustentável da mesma forma em que o incentivo à transparência e ao compartilhamento de bases de dados são relevantes para o acompanhamento dos indicadores de desenvolvimento pela população, de acordo com a legislação de segurança da informação. É possível relacionar o indicador 12 - Efetividade dos Conselhos Municipais de Defesa do Meio Ambiente com o ODS 17 (metas 17.14 e 17.18). Seguindo a mesma essência que propõem as políticas nacional e estadual de meio ambiente, a Lei Complementar $n^{\circ}$ 140/2011 discorre sobre a promoção da educação ambiental em todos os níveis de ensino como competência de cada município, além da necessidade da conscientização pública como peça chave na proteção ambiental. Portanto, justifica-se a relação existente entre o indicador I3 - Implementação da Política Municipal de Educação Ambiental e os ODS 4 (metas 4.7 e 4.c), 13 (13.3), 16 (metas 16.6 e 16.b) e 17 (metas 17.7 e 17.16). Nesse segmento, foi constatado que o indicador 14 - Implementação de Tecnologias Sustentáveis está alinhado aos ODS 8 (meta 8.9), 9 (metas 9.4 e 9.b), 12 (metas 12.4, 12.6 e 12.a) e 17 (meta 17.14), conforme Quadro 1.

Quanto ao Eixo 2, Saneamento Ambiental e Saúde Pública, este é composto por cinco indicadores ambientais: Sistema de Esgotamento Sanitário e Sistema de Abastecimento de Água, Infestação por Aedes aegypti, Inclusão Social dos Catadores de Materiais Recicláveis, Disposição Final de Resíduos Sólidos Urbanos e Gestão Integrada dos Resíduos Sólidos, cujas variáveis 
ambientais totalizam 14. O resultado da análise dos indicadores ambientais do Eixo 2 está no Quadro 2.

Quadro 2 - Indicadores Ambientais do Eixo Temático 2: Saneamento Ambiental e Saúde Pública e sua aderência aos ODS.

\begin{tabular}{|c|c|}
\hline Indicadores Ambientais & $\begin{array}{l}\text { Agenda 2030-ODS (Instituto de Pesquisa } \\
\qquad \text { Econômica Aplicada, 2018) }\end{array}$ \\
\hline $\begin{array}{l}\text { I5 - Gestão Integrada dos Resíduos Sólidos } \\
16 \text { - Disposição Final de Resíduos Sólidos Urbanos } \\
\text { I7 - Inclusão Social dos Catadores de Materiais } \\
\text { Recicláveis } \\
\text { I8 - Infestação por Aedes aegypti } \\
\text { I9 - Sistema de Esgotamento Sanitário e Sistema de } \\
\text { Abastecimento de Água }\end{array}$ & $\begin{array}{l}\text { ODS } 1 \text { (metas } 1.4 \text { e } 1 . a), 3 \text { (metas } 3.3 \text { e } 3.9 \text { ), } 6 \\
\text { (metas } 6.1,6.2,6.3,6.4 \text { e } 6 . b), 8 \text { (meta } 8.3), 9 \text { (meta } \\
9.4 \text { ), } 11 \text { (metas } 11.1 \text { e } 11.6), 12 \text { (metas } 12.4 \text { e } 12.6 \text { ), } \\
16 \text { (meta 16.b) e } 17 \text { (metas } 17.1 \text { e 17.14). }\end{array}$ \\
\hline
\end{tabular}

Fonte: Elaborado pelas autoras (2021).

O Índice Municipal de Qualidade do Meio Ambiente (IQM), que integra as variáveis do eixo 2, foi instituído pelo Decreto Estadual $n^{\circ} 29.306 / 2008$, posteriormente modificado pelo Decreto Estadual $n^{\circ} 32.483 / 2017$, e dispõe sobre o uso de recursos destinados aos municípios com o objetivo de proporcionar uma melhoria na qualidade ambiental; recursos esses liberados pela União e pelo Estado de acordo com a Política Nacional de Resíduos Sólidos e Política Estadual de Resíduos, respectivamente. Ademais, as Políticas Nacional e Estadual de Resíduos Sólidos dispõem sobre disposição final ambientalmente adequada em aterros sanitários, seguindo as normas e padrões específicos.

No que tange ao incentivo de recursos internos para práticas sustentáveis, o indicador 15 Gestão Integrada dos Resíduos Sólidos pode ser relacionado ao ODS 17 (meta 17.1) ao passo que o indicador 16 - Disposição Final de Resíduos Sólidos Urbanos possui relação com ODS 11 (meta 11.6). Ainda a respeito da Política Estadual de Resíduos Sólidos, essa institui o Programa Bolsa Catador (Art. 65), regulamentado pelo Decreto Estadual $n^{\circ} 33.361 / 2019$, promovendo o tratamento dos resíduos concomitantemente com a inclusão social dos catadores. A Política Nacional afirma a importância das instituições na vida social e econômica dos catadores e catadoras. Assim, é possível relacionar o indicador 17 - Inclusão Social dos Catadores de Materiais Recicláveis com os ODS 1 (metas 1.4 e 1.a) e 8 (meta 8.3). A Lei Federal n 13.301/2016 apresenta meios para a vigilância em situações que ofereçam risco à saúde pública, salientando a relevância de atividades de limpeza em imóveis que mobilizem a participação da população e a necessidade de campanhas educativas, orientando a comunidade. A partir dessas medidas, percebe-se que o número de casos de doenças provocadas pelo mosquito Aedes aegypti, pode ser controlado e reduzido. Diante disso, é perceptível a aderência do indicador 18 com o ODS 3 (meta 3.3).

As diretrizes nacionais de saneamento básico em âmbito nacional, dispostas pela Lei 
Federal $n^{\circ} 11.445 / 2007$, discorrem sobre o direito à universalização do acesso ao saneamento que abrange o abastecimento de água, o tratamento do esgotamento sanitário, drenagem urbana e a limpeza e o manejo dos resíduos sólidos exercidos de maneira ambientalmente correta. Quanto à prestação desses serviços, é estabelecido que a União pode delegar às instituições estaduais e municipais. Em âmbito estadual, a Lei Complementar nº 162/2016 instituiu a Política Estadual de Abastecimento de Água e de Esgotamento Sanitário no Estado do Ceará, a qual estabelece que o acesso à água potável e ao esgotamento sanitário é direito essencial a todos, assegurando tanto o abastecimento como tratamento seguro, seguindo padrões de qualidade específicos.

Foi possível estabelecer a relação entre o indicador 19 - Sistema de Esgotamento Sanitário e Sistema de Abastecimento de Água com os ODS 1 (meta 1.4), 3 (metas 3.3 e 3.9), 6 (metas 6.1, 6.2, 6.3, 6.4 e 6.b), 9 (meta 9.4), 11 (meta 11.1), 12 (metas 12.4 e 12.6), 16 (meta 16.b) e 17 (meta 17.14). A Política Nacional de Resíduos Sólidos e a Política Estadual de Resíduos Sólidos do Ceará descrevem a responsabilidade compartilhada no que trata do ciclo de vida dos produtos fabricados com o objetivo de acabar ou diminuir a quantidade de resíduos e rejeitos e proporcionar a disposição final adequada. Ademais, a Resolução CONAMA n 430/2011 e a Resolução COEMA n 2/2017 abordam o lançamento de efluentes em corpos receptores atribuindo a responsabilidade pelo despejo aos incumbidos, os quais devem priorizar o uso de métodos de tratamentos ambientalmente seguros concomitante com o incremento de meios e processos limpos e sustentáveis.

O Eixo 3 - Recursos Hídricos, com 3 variáveis ambientais, tem aderência a 8 metas dos ODS 3, 6 e 11, conforme o Quadro 3.

Quadro 3 - Indicadores Ambientais do Eixo Temático 3 - Recursos Hídricos e sua aderência aos ODS.

\begin{tabular}{l|l}
\hline Indicadores Ambientais & \multicolumn{1}{|c}{ ODS - Agenda 2030 } \\
& \multicolumn{1}{|c}{ (Instituto de Pesquisa Econômica Aplicada, 2018) } \\
\hline I10 - Melhoria da Qualidade da Água. & $\begin{array}{l}\text { ODS 3 (meta 3.9), 6 (metas 6.1, 6.2, 6.3, 6.4 e 6.a e } \\
\text { 6.b) e 11 (meta 11.1). }\end{array}$ \\
\hline
\end{tabular}

Fonte: Elaborado pelas autoras (2021).

O Eixo 3, sobre recursos hídricos, traz o indicador ambiental I10- Melhoria da Qualidade de Água, que possui relação com o ODS 3 da Agenda 2030 por meio da meta 3.9, que diz respeito à redução do número de mortes relacionado a doenças vinculadas à contaminação através da água e outros meios naturais, pois existe, dentre suas variáveis ambientais, a preocupação em mensurar o percentual do cumprimento da meta referente a vigilância do Parâmetro Bacteriológico (coliforme total/E.coli), evitando assim doenças de veiculação hídrica.

O eixo também traz variáveis a respeito da implementação de projetos municipais para assegurar o uso racional da água por meio de parcerias governamentais, bem como percentual de mensuração da população com cobertura de abastecimento de água tratada. Assim suas variáveis têm forte relação com o ODS 6 , que trata da garantia ao acesso à água e ao saneamento básico. 
As metas desse objetivo que se relacionam com o indicador são as de números 6.1, 6.2, 6.3, 6.4, 6.a e 6.b. As seis metas possuem aderência com as variáveis ambientais do eixo 3 pois tratam de propostas que asseguram o uso racional da água por meio de tecnologias de uso, reciclagem e a garantia eficiente da água a todos, bem como sobre o alcance universal e igualitário à água potável a todos até o ano de 2030.

O ODS 11 por meio da meta 11.1 tem aderência ao eixo 3, considerando que tem por objetivo garantir o acesso de todos à habitação segura, adequada e a preço acessível, e aos serviços básicos e urbanizar as favelas, pois garantir água tratada à população e, principalmente, às mais carentes é um serviço básico para a dignidade humana.

Concernente ao eixo 4 - Agricultura Sustentável, com 2 variáveis ambientais, observa-se que tem aderência a 3 metas do ODS 2, consoante se verifica no Quadro 4.

Quadro 4 - Indicadores Ambientais do Eixo Temático 4: agricultura sustentável e sua aderência aos ODS

\begin{tabular}{l|c}
\hline Indicadores Ambientais & $\begin{array}{c}\text { ODS - Agenda 2030 } \\
\text { (Instituto de Pesquisa Econômica Aplicada, 2018) }\end{array}$ \\
\hline I11- Manejo sustentável da Produção & \\
Agropecuária; & ODS 2 (metas 2.a, 2,3 e 2,4). \\
I12 - Capacitação em Agricultura & \\
Sustentável. & \\
Fonte: Elaborado pelas autoras (2021).
\end{tabular}

As variáveis do eixo 4 se relacionam com o ODS 2 da Agenda 2030 (Fome Zero e Agricultura Sustentável), por meio das metas 2.a, 2,3 e 2,4. As metas 2.4 e 2.a guardam relação com o indicador 111 por proporem a implementação de práticas e métodos sustentáveis, contribuindo assim para melhoria e aumento na produção agropecuária local. A meta 2.3, que tem por objetivo dobrar a produtividade agrícola e a renda dos pequenos produtores de alimentos, sendo parte desses produtores os agricultores familiares, possui relação com o indicador 112 , pois visa incentivar o aumento do número de agricultores capacitados em pequenas comunidades familiares, contribuindo assim para diminuição do desemprego e proporcionar a garantia de alimentos saudáveis a todos.

No que diz respeito ao Eixo 5, com 20 variáveis ambientais, o Quadro 5 mostra quais são as metas aderentes à Agenda 2030. 
Quadro 5 - Indicadores Ambientais do Eixo Temático 5: biodiversidade e mudanças climáticas e sua aderência aos ODS

Indicadores Ambientais

ODS - Agenda 2030

(Instituto de Pesquisa Econômica Aplicada, 2018)

113 - Unidades de Conservação municipais;

114 - Áreas verdes urbanas;

115 - Preservação e conservação da

biodiversidade;

I16 - Controle de desmatamento e queimadas.

ODS 2 (meta 2.5 e 2.a), 11 (metas 11.7 e 11.b), 12 (meta 12.2), 13 (meta 13.1 e 13.2) e 15 (metas 15.1, 15.2 , 15.3, 15.4, 15.5, 15.6, 15.7, 15.8, 15.9, 15.a, 15.b e 15.c)

Fonte: Elaborado pelas autoras (2021).

O referido eixo tem aderência a 5 ODS, a saber: ODS 2, 11, 12, 13 e 15, sendo o ODS 15 com aderência em suas 12 metas, pois têm por objetivo promover a proteção, recuperação e proporcionar o uso sustentável de todos os ecossistemas terrestres e com isso, promover a gestão desses espaços de forma sustentável.

As variáveis 'd' e 'e' do indicador I13 tratam sobre a existência de Conselhos Gestores nas unidades de conservação municipais. Essas variáveis têm relação com o ODS 12, por meio da meta 12.2 que tem por objetivo alcançar a gestão sustentável e o uso eficiente dos recursos naturais. Quanto às variáveis ' $f$ ' e ' $g$ ' de referido indicador estão relacionadas especificamente com a meta 15.b do ODS 15 que fala sobre a mobilização de recursos para financiamento que proporcionem o manejo sustentável, pois essas variáveis, respectivamente, questionam se as Unidades de Conservação Municipais possuem Plano de Manejo e se as Reservas Particulares do Patrimônio Natura possuem Plano de Manejo.

Algumas variáveis do eixo 5 têm aderência com o ODS 11 (Cidades e Comunidades Sustentáveis), meta 11.7, que tem o objetivo de proporcionar o acesso universal a espaços públicos seguros, inclusivos, acessíveis e verdes a todos, como também têm relação com o ODS 15 (Vida Terrestre) através das metas 15.1 e 15.2 .

O indicador I14 (Áreas verdes urbanas) traz 4 variáveis ambientais, as quais buscam avaliar se os municípios possuem: a) lei de arborização municipal; b) total de áreas verdes por habitante; c) plano de Arborização Urbano Implantado; e d) o município possui viveiro ou banco de mudas.

A variável de item 'd' do indicador 114 se relaciona com o ODS 2 (Fome zero e agricultura sustentável) com as metas de número 2.5 e 2.a. A meta 2.5 tem por objetivo garantir a conservação da diversidade genética de sementes, plantas cultivadas, dentre outras espécies de seres vivos, inclusive por meio de bancos de sementes e plantas. A meta 2.a tem por finalidade incentivar o investimento, inclusive por meio de reforço da cooperação internacional, em pesquisa, infraestrutura rural, bancos de genes de plantas e animais, dentre outras técnicas de manejo, com objetivo de aumentar a capacidade da produção agrícola nos países em desenvolvimento. 
Essa variável também tem aderência com os ODS 11 e 15 através da meta 11.7 que tem por objetivo proporcionar o acesso universal a espaços públicos seguros, inclusivos, acessíveis e verdes a todos, uma vez que a criação de viveiros e banco de mudas garantirá que tanto as futuras como a atual população tenham áreas verdes preservadas. Referente ao ODS 15 por meio da meta 15.5 que tem como objetivo tomar medidas urgentes e significativas para reduzir a degradação de habitat naturais, deter a perda de biodiversidade de espécies ameaçadas, os viveiros e bancos de mudas são medidas que garantirão a preservação de espécies de plantas importantes para o ecossistema.

A variável de item 'a' do indicador 15 (115) que trata sobre o município possuir Projetos de Conservação e Preservação da Biodiversidade, mostrou-se aderente ao ODS 15 e às metas de número 15.1, 15.4, 15.5, 15.a e 15.b. Tais metas buscam promover o uso sustentável da biodiversidade e dos ecossistemas, promover a proteção de espécies em extinção. Houve ainda uma aderência com o ODS 12 através da meta 12.2 que tem por objetivo alcançar até 2030 a gestão sustentável e o uso eficiente dos recursos naturais.

O indicador 116 (Controle de Desmatamento e Queimadas) traz 4 variáveis sobre a competência dos municípios em disciplinar as atividades previstas em seu território, por meio de ações administrativas no combate ao desmatamento e às queimadas.

O indicador I16 apresenta relação com a meta 15.2 do ODS 15 (Vida Terrestre) que diz que, até 2020, deve-se promover a implementação da gestão sustentável de todos os tipos de florestas, deter o desmatamento, restaurar florestas degradadas e aumentar substancialmente 0 florestamento e o reflorestamento globalmente. Foi encontrada aderência também com as metas 13.1 e 13.2 do ODS 13 (Ação contra a mudança global do clima). A meta 13.1 diz respeito a reforçar a resiliência e a capacidade de adaptação a riscos relacionados ao clima e às catástrofes naturais, pois essa medida de proteção pode evitar as queimadas que ocasionam problemas como a diminuição da biodiversidade, emissão de gases poluentes na atmosfera, piorando a qualidade do ar, como também o aumento das doenças respiratórias. A meta 13.2 tem por objetivo integrar medidas da mudança do clima nas políticas, estratégias e planejamentos em âmbito nacional nos países-membros.

Por fim, a variável de item 'd' do indicador 116 busca saber se os municípios possuem programas/projetos com foco nas mudanças climáticas e está relacionada com a meta 11.b do ODS 11 (Cidades e comunidades sustentáveis), pois essa meta tem por objetivo aumentar o número de cidades com políticas e planos relacionados às mudanças climáticas e desastres naturais.

\section{Considerações Finais}

Os resultados apontam que o Programa Selo Município Verde (PSMV) se mostra como uma importante ferramenta na territorialização da gestão ambientalmente adequada na esfera local, promovendo a responsabilidade aos municípios quanto à compatibilização dos diversos setores 
com as dimensões da sustentabilidade e incorporando a Agenda 2030 e os ODS em suas políticas públicas.

A partir dos resultados encontrados é possível afirmar que houve significativo alinhamento dos eixos temáticos do PSMV com os Objetivos do Desenvolvimento Sustentável, o que permite inferir que o programa de certificação ambiental cearense abrange temáticas relevantes ao alcance da qualidade ambiental para todos, buscando solucionar problemáticas locais e caminhar em direção de um desenvolvimento social, ambiental e econômico. Em síntese, os eixos incorporaram 13 dos 17 ODS, sendo eles: ODS 1, 2, 3, 4, 6, 8, 9, 11, 12, 13, 15, 16 e 17, ressaltando os ODS 6, 15 e 17 como os que mais aparecem nas aderências.

Este estudo permite garantir que o investimento dos gestores locais, na busca pela certificação do PSMV deve beneficiar a mobilização de esforços para a implementação da Agenda 2030 para o Desenvolvimento Sustentável no território municipal. Além disso, coloca o poder local como um aliado no alcance da proposta da Agenda ambiental de desenvolvimento.

Por fim, é interessante a realização de novos trabalhos para dar continuidade ao monitoramento da aderência das outras edições do Programa Selo Município Verde com os Objetivos do Desenvolvimento Sustentável, analisando sua contribuição para a gestão municipal no cumprimento da Agenda 2030.

\section{Agradecimentos}

As autoras agradecem ao Laboratório de Energias Renováveis e Conforto Ambiental (Lerca), do Departamento da Construção Civil, do IFCE campus Fortaleza. Agradecem também ao suporte financeiro por meio de bolsa de iniciação científica da FUNCAP (Edital nº 02/2019/PRPI-Reitoria) e do IFCE.

\section{Colaboradores}

D. OLIVEIRA, A. LIMA, N. CABRAL e P. LIMA colaboraram de forma igual na redação, desenvolvimento, tratamento de dados e revisão do artigo.

\section{Referências}

Bardin, L. Análise de Conteúdo. 70. ed. São Paulo: Almedina, 2011.

Cabral, N. R. A. J. et al. Índice de Sustentabilidade Ambiental: um instrumento de redistribuição de incentivos econômicos para a conservação ambiental nos municípios do Ceará. In: Holanda, M. C.; Carvalho, E. B. S; Barbosa, M. P. (org.). Economia em Ceará em Debate. 3. ed. Fortaleza: IPECE, 2008. p. 158-174.

Cabral, N. R. A. J.; Lima, P. V. P. S.; Azevedo, M. S. F. Manual técnico: Programa Selo Município Verde. 19. ed. Fortaleza: Secretaria de Meio Ambiente, 2019.

Dos Santos, F. M. Análise de conteúdo: a visão de Laurence Bardin. Revista Eletrônica de Educação, v. 6, n. 1, p. 383-387, 2012.

Instituto de Pesquisa Econômica Aplicada. Agenda 2030 ODS: metas nacionais dos objetivos de desenvolvimento sustentável. Brasília: IPEA, 2018. Disponível em: https://www.ipea.gov.br/portal/images/stories/PDFs/livros/livros/180801_ods_metas_nac_dos_obj_ 
de_desenv_susten_propos_de_adequa.pdf. Acesso em: 4 out. 2021.

Lima, A. K. S. Relação dos indicadores ambientais do Programa Selo Município Verde com os objetivos do desenvolvimento sustentável. 2020. 46 f. Monografia (Graduação) - Instituto Federal de Educação, Ciência e Tecnologia do Ceará, Fortaleza, 2020. Disponível em: http://biblioteca.ifce.edu.br/index.asp?codigo_sophia=98632. Acesso em: 5 out. 2021.

Neves, J. W. M. Sustentabilidade ambiental: instrumento para apoiar decisões na gestão pública das cidades. In: $30^{\circ}$ Seminário de Iniciação Científica e Tecnológica. Florianópolis, Santa Catarina: UFSC, 2020. Disponível em https://repositorio.ufsc.br/handle/123456789/210287. Acesso em: 5 out. 2021.

Programa das Nações Unidas para o Desenvolvimento. Preâmbulo do documento Transformando Nosso Mundo: a agenda 2030 para o desenvolvimento sustentável. Brasília: PNUD, 2020.

Roma, J. C. Os objetivos de desenvolvimento do milênio e sua transição para os objetivos de desenvolvimento sustentável. Ciência e cultura, v. 71, n. 1, p. 33-39, 2019.

Secretaria do Meio Ambiente do Ceará. Cartilha Município Verde. Fortaleza: Governo do Estado do Ceará, [2005]. Disponível em: https://www.sema.ce.gov.br/wpcontent/uploads/sites/36/2013/02/CARTILHA-SELO-VERDE-17_05_06.pd. Acesso em: 5 out. 2021.

Como citar este artigo/How to cite this article

Oliveira, D. R. et al. Programa Selo Município Verde e a efetividade dos Objetivos Do Desenvolvimento Sustentável. Sustentabilidade: Diálogos Interdisciplinares, v. 2, e215529, 2021. https://doi.org/10.24220/2675$\underline{7885 \mathrm{v} 2 \mathrm{e} 2021 \mathrm{a} 5529}$

Recebido em 9 de dezembro de 2021 e aprovado em 14 de dezembro de 2021. 